\title{
Simulation on Occupant Evacuation at a Public Site Based on SMARTFIRE and Building EXODUS
}

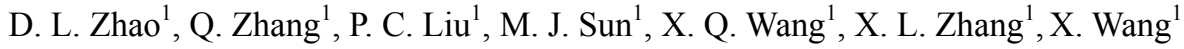 \\ ${ }^{1}$ Shanghai Institute of Technology, Shanghai, China \\ Correspondence: D. L. Zhao, College of Urban Construction and Safety Engineering, Shanghai Institute of Technology, \\ China.
}

Received: July 23, 2017 Accepted: August 28, $2017 \quad$ Online Published: August 29, 2017

doi:10.11114/set.v5i1.2627 URL: https://doi.org/10.11114/set.v5i1.2627

\begin{abstract}
In this paper, the software of SMARTFIRE is applied to simulation a fire process at a long-distance passenger transport station. The results of SMARTFIRE can be used as environment condition of occupant evacuation. The software of Building EXODUS is applied to simulation the evacuation process with and without fire. Evacuation times with different number of occupants are calculated. If the density of occupants is relatively small, pedestrian flow during evacuation can take on a dilute state because of the large quantity of exits on public site. And evacuation time changes a little with the increase of the number of occupants in low range of density. If the density of occupants is comparatively big, the phenomena of queuing up at the exits and assembling at the bottlenecks will take place, resulting in an obviously long evacuation time; The influences of the use ratios of exit are analyzed, and balancing the use ratio of each exit can obviously improve the efficiency of evacuation; The influences of the fire simulated by SMARTFIRE are also analyzed. In addition to the factors of low visibility and low walking speed, the change of evacuation routes and the imbalance of the use ratio of each exit are also very important factors of fire.
\end{abstract}

Keywords: occupant evacuation, fire, Building EXODUS, SMARTFIRE, public site

\section{Introduction}

In recent years, the problems on occupant evacuation at public site in an emergency have attracted more and more attention of scholars. The basic data of evacuation behavior can be obtained by investigation after the disaster, evacuation rehearsal, questionnaire investigation, and etc. Occupant behavior in evacuation can be studied with the knowledge of various subjects, such as statistics, psychology, physiology, behavioral science and artificial intelligence (Jiang, Deng, Hu, Ding \& Chow, 2009; Sun \& Bauke, 2009).

From 1970's, research on computer simulation on occupant evacuation has been carried on for more than forty years. Evacuation dynamic models can be classified as macroscopic models and microcosmic models. Macroscopic model theory was introduced by Henderson, taking the interaction of occupants into account but ignores individual differences (Henderson, 1974); Microcosmicmodels which can describe the details of individual behavior, can be classify as continuous models and discrete models. Representative microcosmic models are social force model (Helbing, 1994; Helbing, Farkas \& Vicsek, 2000; David, 2000) and Cellular Automaton models (Zhao, Yang \& Li, 2006; Zhao, Yang, Li \& Zo, 2006).

Occupant evacuation models also can be classified as the following three types: 1, Movement models, such as WAYOUT, TIMTEX, FPETool, EVACNET, Takahashi's Fluid Model, PathFinder, STEPs, and etc. 2, Local behavior models, such as EXIT89, Simulex, ALLSAFE, GridFlow, PEDROUTE/PAXPORT (Buckmann \& Leather), and etc. 3, Behavior models, such as Building EXODUS, Egress, Legion, VEgAS, EXITT, E-SCAPE, BGRAF, and etc. In recent years, model research on occupant evacuation in fire has been developed very quickly, such as FDS+Evac (Ehtamo, Heliövaara, Korhonen \& Hostikka, 2010; Korhonen, Hostikka, Heliövaara \& Ehtamo, 2008).

The software simulation fire development process is also improved, and it is applied to the construction fire safety assessment. The related characteristics of fire flue gas, such as concentration, toxicity, radiation heat, etc., are the key factors that affect evacuation in buildings. By setting up fire scene, analyzing the diffusion process and distribution characteristics of smoke in building structure is an important basis for analysis and improvement of building evacuation strategy. There are many mature fire simulation software applications in practical engineering, such as FDS, ANSYS, FLUENT, PHOENICS, etc. 
In this paper, the software of SMARTFIRE (Ewer, Jia, Grandison, Galea \& Patel, 2008) is applied to simulate the fire process at a long-distance passenger transport station. Then, the software of Building EXODUS is applied to analyze the evacuation process with and without fire (Gale, Lawrence, Gwynne, Filippidis, Blackshields \& Cooney, 2006).

\section{Introduction of SMARTFIRE and Building EXODUS}

The software of SMARTFIRE and Building EXODUS are developed by the Fire Safety Engineering Group (FSEG) at the University of Greenwich.

\subsection{Description of the Software SMARTFIRE}

SMARTFIRE is a complete fire field modeling environment that employs state-of-the-art finite volume methods. As shown in Fig.1, it has four main logical components, namely: a scenario designer for importing DXF formatted CAD drawings, a front end case specification environment, an automated interactive meshing system and a CFD numerical engine.

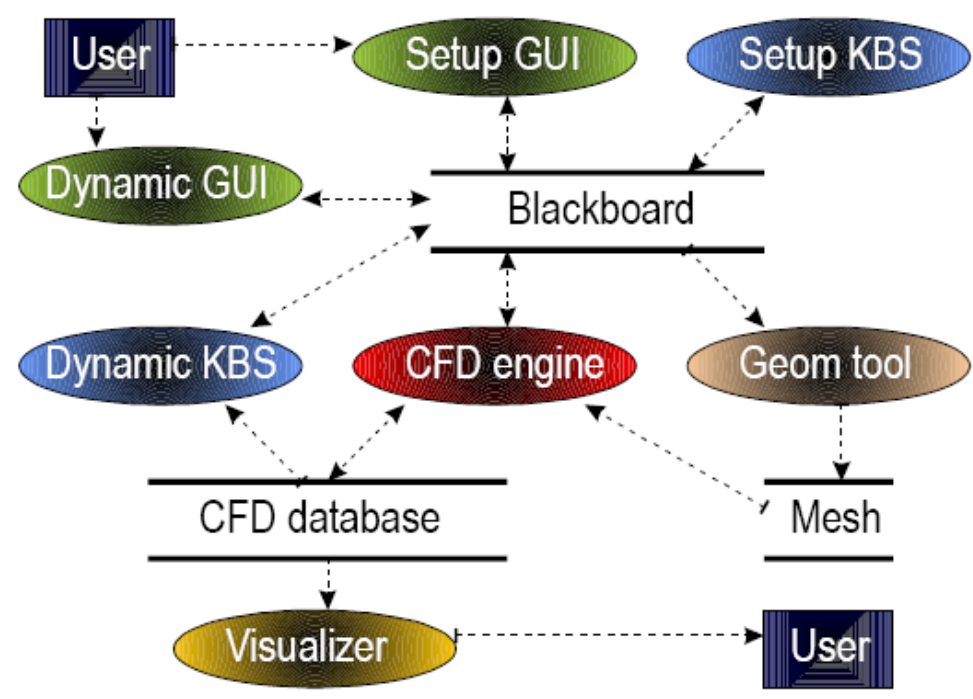

Figure 1. Modular architecture of SMARTFIRE

The CFD software is capable of simulating hot, turbulent, buoyant flows modeled in a single arbitrarily sized region, which may contain multiple internal compartments that are separated by walls and partitions. Fires can be represented as volumetric heat sources or as mass sources of a gaseous fuel. Thermal radiation may be modeled using radiosity, an enhanced six-flux radiation model or a multiple ray radiation model. Turbulence is modeled using a buoyancy modified k-epsilon model. The general flow can be either compressible or incompressible and is modeled using one of the pressure-correction algorithms. In this paper, using SMARTFIRE V4.3.

\subsection{Description of the Software Building EXODUS}

Building EXODUS is used to simulate the evacuation and movement of large numbers of individuals within building. The software EXODUS takes into consideration people-people, people-fire, and people-structure interactions. It has been written in $\mathrm{C}++$ using Object Orientated techniques and rule-base concepts to control the simulation. As shown in Fig.2, the rules of building EXODUS can be categorized into five interacting sub-models, the OCCUPANT, MOVEMENT, BEHAVIOUR, TOXICITY and HAZARD sub-models. 


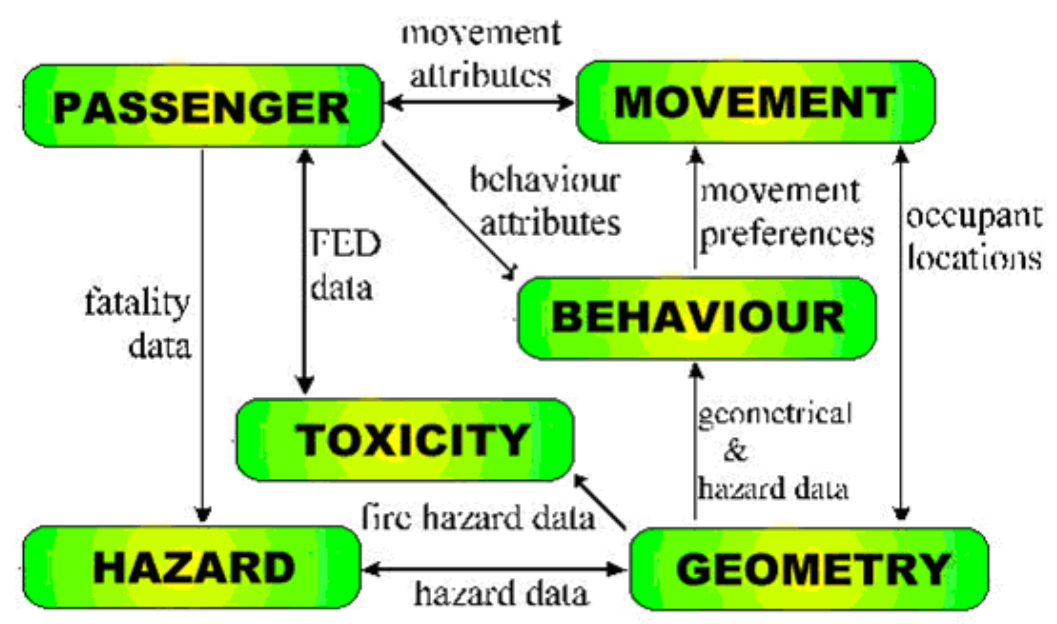

Figure 2. EXODUS sub-model interaction

Geometries are represented as two-dimensional grids. Each location on a grid is called a node, and each node may be linked to its nearest neighbors by four or eight arcs. Walking speed and direction can be adjusted according to the change of environment, such as the crowd density and the distribution of obstacles. Occupants always move from the node of high danger grade to the node of low danger grade and eventually toward the exits. In this paper, using building EXODUS V6.1.

\section{Geometry Modeling of the Station}

The long-distance passenger transport station covers an area of 9470 square meters. Only the geometry of the first floor is modeled in this paper. The architectural plan (DXF file) is input into the Scenario Designer of SMARTFIRE as shown in Fig. 3(a). The floors, rooms, doors, windows, ignition sources, combustible materials, and etc. are described with Scenario Designer tools. Then the whole construction is represented by a three dimensional grid as shown in Fig. 3(b). Some parameters such as the type and quantity of combustible materials, thermal properties, and etc., need to be assumed. 


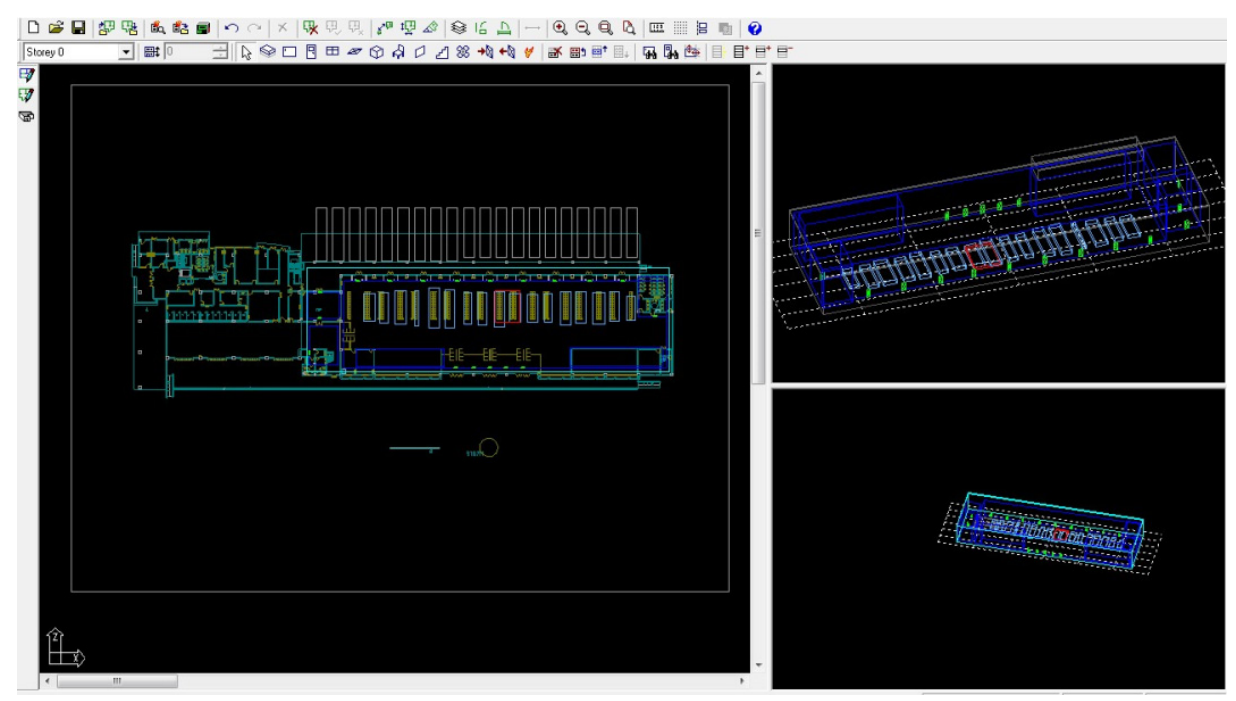

(a) SMARTFIRE Scenario Designer

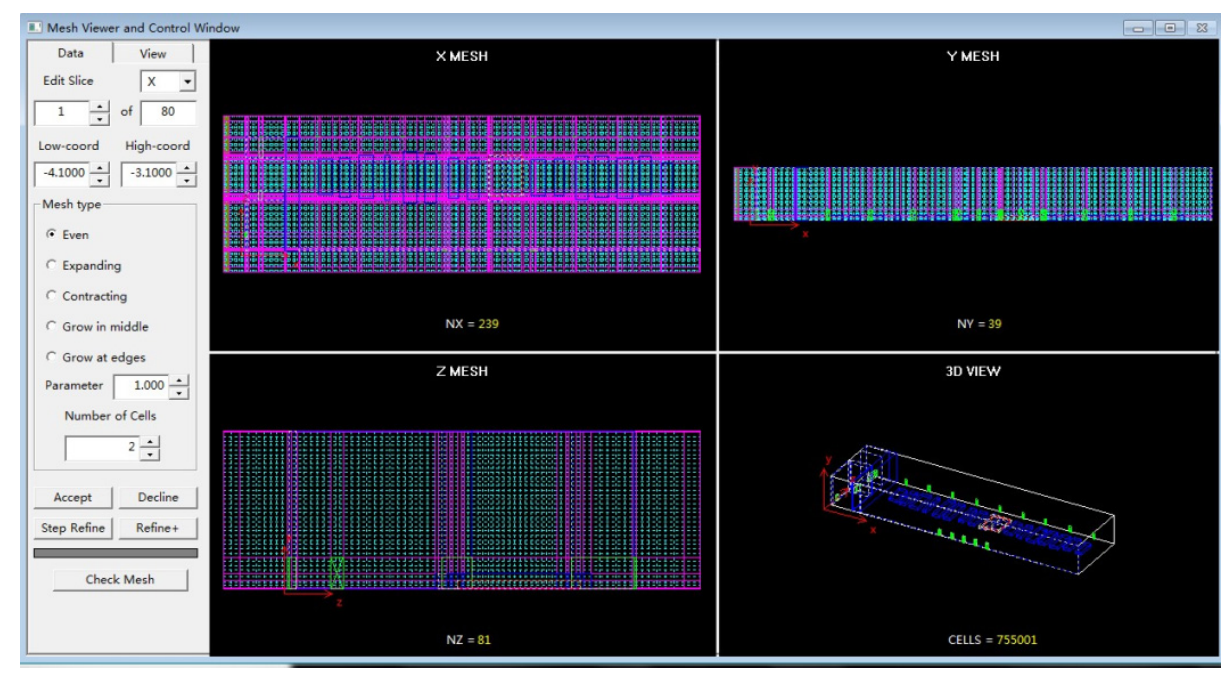

(b) Gridding

Figure 3. Geometry modeling of the station

\section{Simulation by CFD Engine}

The operation interface of the CFD engine of SMARTFIRE is shown as Fig. 4. The results including the values of pressure, propagation velocity in $\mathrm{X}, \mathrm{Y}, \mathrm{Z}$ directions, enthalpy, fire kinetic energy, dissipation rate, temperature, smoke buoyancy, and smoke density are shown in Table. 1. 


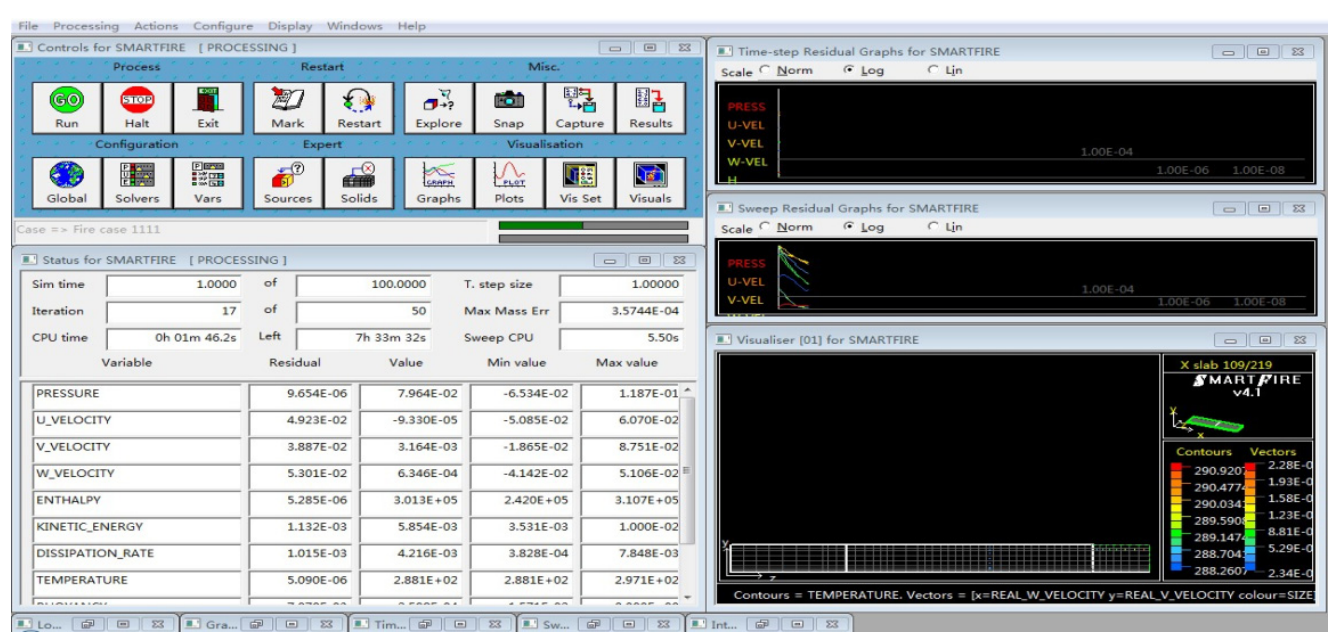

Figure 4. Operation interface of CFD engine

Table 1. Results by CFD engine

\begin{tabular}{cccc}
\hline Variable & Average value & Minimum value & Maximum value \\
\hline Pressure & $6.170 \mathrm{E}-02$ & $-2.543 \mathrm{E}-01$ & $8.763 \mathrm{E}-02$ \\
X_velocity & $-8.858 \mathrm{E}-04$ & $-2.087 \mathrm{E}-01$ & $2.293 \mathrm{E}-01$ \\
Y_velocity & $3.055 \mathrm{E}-02$ & $-6.251 \mathrm{E}-02$ & $2.520 \mathrm{E}-01$ \\
Z_ velocity $_{\text {E }}$ & $-5.085 \mathrm{E}-04$ & $-1.937 \mathrm{E}-01$ & $2.224 \mathrm{E}-01$ \\
Enthalpy & $3.014 \mathrm{E}+05$ & $2.420 \mathrm{E}+05$ & $3.198 \mathrm{E}+05$ \\
Kinetic energy & $3.796 \mathrm{E}-03$ & $1.620 \mathrm{E}-03$ & $1.000 \mathrm{E}-02$ \\
Dissipation rate & $2.069 \mathrm{E}-03$ & $2.000 \mathrm{E}-04$ & $7.848 \mathrm{E}-03$ \\
Temperature & $2.822 \mathrm{E}+02$ & $2.881 \mathrm{E}+02$ & $3.058 \mathrm{E}+02$ \\
Buoyancy & $-7.031 \mathrm{E}-04$ & $-3.042 \mathrm{E}-02$ & $0.000 \mathrm{E}+00$ \\
Density & $1.240 \mathrm{E}+00$ & $1.169 \mathrm{E}+00$ & $1.600 \mathrm{E}+03$
\end{tabular}

\section{Evacuation Simulation by Building EXODUS}

The whole construction is represented by a two dimensional grid. Each node represents $0.5 \mathrm{~m} \times 0.5 \mathrm{~m}$, which can hold only one person, or be empty, or be occupied by obstacle. The OCCUPANT sub-model defines each individual as a collection of attributes which broadly fall into four categories, physical, psychological, experiential and hazard effects. The Target Door attribute allows an occupant to be directed to a specific external door, regardless of the potential map. The values this attribute may take are the names of the exits in the geometry. The default value is "Nearest Door", i.e. follow the potential map, which is applied in this paper. Random distribution of occupants in the beginning is taken into account in this study. The pre-movement times, the gender and properties of occupants, the reaction times and the walking speeds are all given as default values.

\subsection{Influence of the Density of Occupants}

The density of occupants is a very importance parameter in the research of occupant evacuation at public site. Remaining the individual properties such as age distribution, walking speed, and reaction time unchanged, the evacuation processes with initially 100, 200, 300, 400, 500 and 1000 occupants are simulated respectively. An example is shown in Fig.5 and all the results are shown in Fig. 6. 


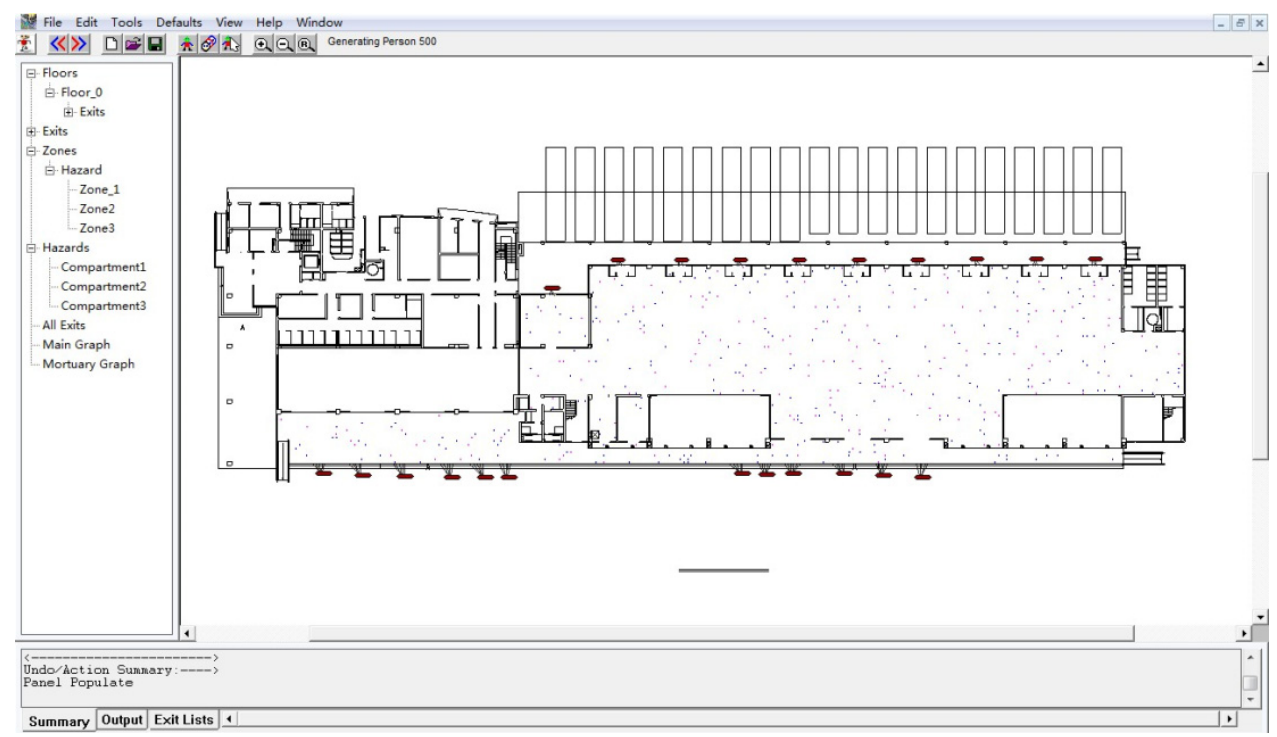

Figure 5. Distribution state of initially 500 occupants

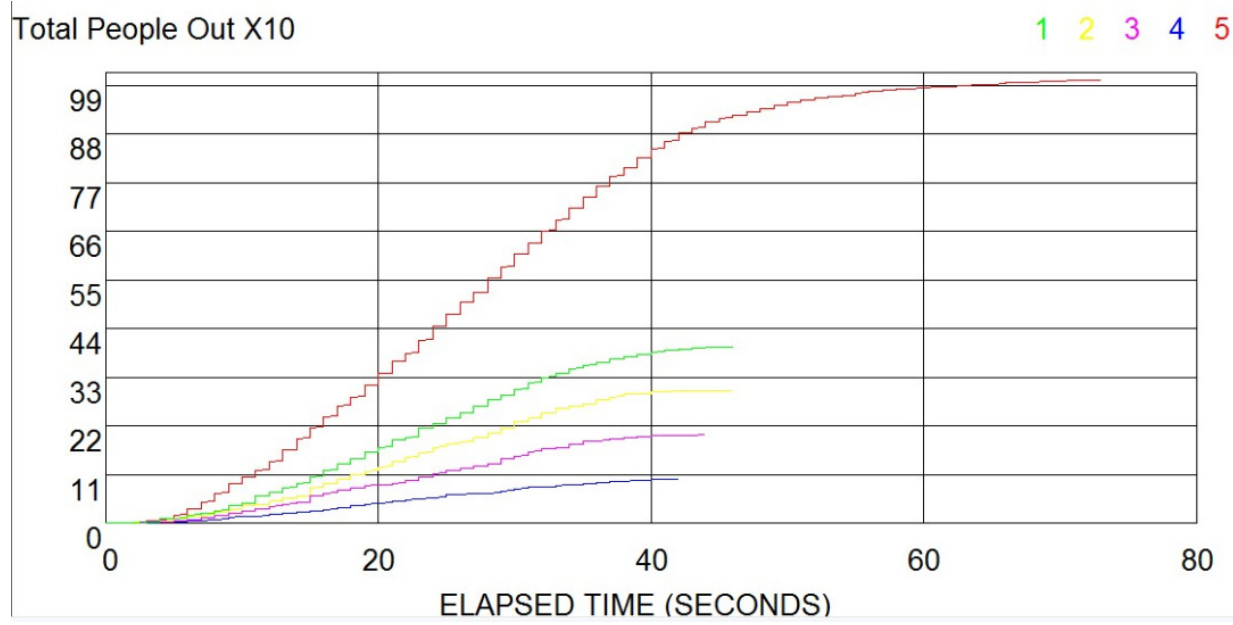

Figure 6. Relations between the number of occupants out and evacuation time

The evacuation times with a total number of 100, 200, 300, 400, 500 and 1000 are 42.63s, 44.73s, 46.72s, 46.06s, $47.78 \mathrm{~s}$ and $73.25 \mathrm{~s}$, respectively. All the data are the mean values of ten times' independent calculations. When the total number of occupants is not big, i.e. relatively low density of occupants, the evacuation time changes a little. It only increases $5 \mathrm{~s}$ when the total number of occupants increases from 100 to 500 . There are plenty of exits in this station, i.e. a total of 22 exits, so the evacuation time is consumed on walking along the evacuation routes instead of queuing up at the exits. The flux of each exit is improved with the increase of the number of occupants, thus the utilization ratio of each exit is improved accordingly. The pedestrian flow takes on a dilute state, thus the evacuation time is not obviously increased. The evacuation time with a total number of 300 is even bigger than that with a total number of 400 for the randomicity of simulation including the random distribution in the beginning.

When the total number is 1000 , i.e. a relatively high density, the evacuation time is prolonged a lot because of the dense pedestrian flow and the phenomenon of queuing up at the exits. Population density in the simulation at 21S are shown in Fig.7.The maximum occupation is coloured red, and the minimum occupation is coloured blue. Congestion area coloured red was shown in Fig.8. 


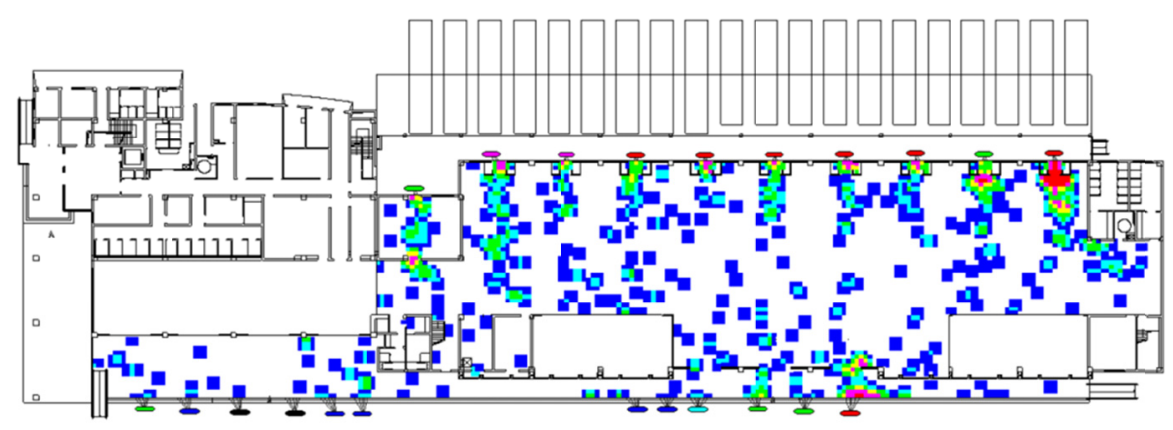

Figure 7. Population density in the simulation at $21 \mathrm{~S}$

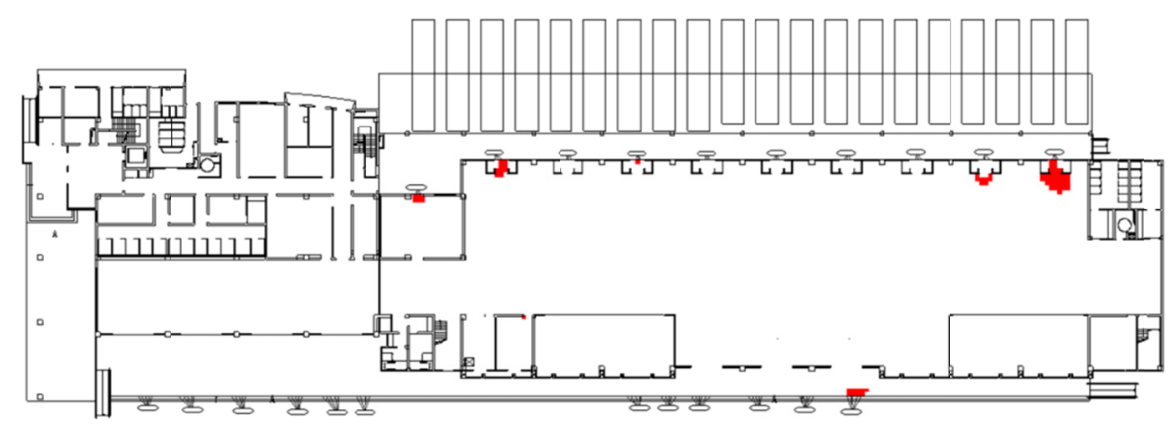

Figure 8. Congestion area in the simulation

\subsection{Influence of the Utilization Ratio of Exits}

Evacuation time is as long as the time it takes to clear the exit with the longest evacuation time. According to the cask effect theory, the shortest board of a barrel decides how much water it can hold. In the same way, evacuation time is determined by the last exit completing evacuation. If the numbers of occupants out from each exit are almost the same, the evacuation time would be the shortest. This theory is simulated in this study.

Taking the evacuation of 500 occupants as an example, the evacuation time is $47.95 \mathrm{~s}$, which is a mean value of 20 times' calculations under the same condition. As shown in Fig. 9(a), the utilization ratios of each exit are very different. The maximum value is $10.2 \%$, while the minimum value is only $0.6 \%$. The utilization ratios of exit 9 , 19 , and 10 are relatively high, while those of exit 15 and 22 are relatively low. In the case of relatively high density of occupants, a lot of time is spent on queuing up for evacuation at the exits with high utilization ratio. 


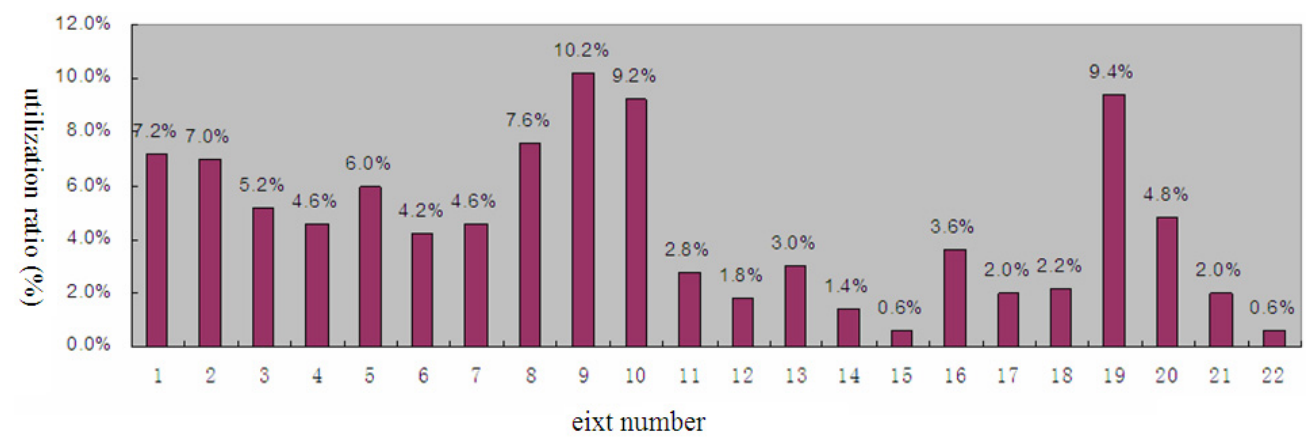

(a) evacuation naturally

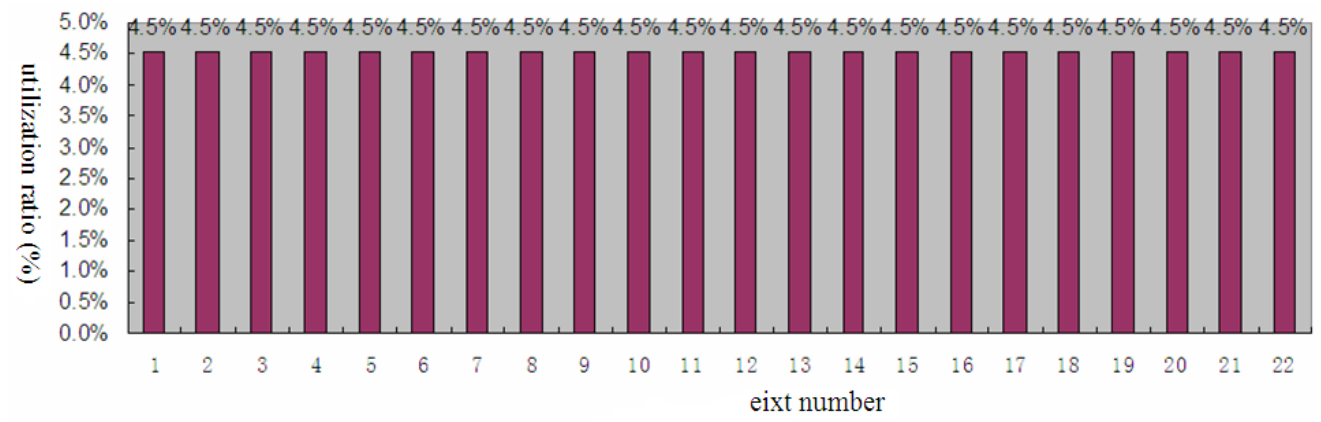

(b) evacuation artificially

Figure 9. Utilization ratios of each exit (500 occupants randomly distributed originally)

In order to validate the cask effect theory, some occupants' evacuation routes are changed artificially to realize a uniform number of occupants using each exit. The properties, such as sexual proportion, walking speed, reaction time, and etc. are not changed at all. The evacuation time is $40.32 \mathrm{~s}$, which is a mean value of 20 times' calculations under the same condition. Compared with $47.95 \mathrm{~s}$, the evacuation time is reduced by $16 \%$, i.e. $7.63 \mathrm{~s}$, which is a very considerable value for safety evacuation, especially when the density of occupants is high. The utilization ratios of each exit by artificial means are shown as Fig.9(b). At densely occupied public site, balancing the utilization ratios of each exit is very benefit for improving the efficiency of evacuation.

A uniform utilization ratio of each exit is an ideal state. In reality, it is very difficult to realize because of nonuniform distribution of occupants, unreasonable location of exits, the psychology of taking the shortest routes or going with the crowd, the blockage of the passage or exit by fire, and etc. While the balance of utilization ratio can be improved by reasonable design of building structure, perfect guide signs on egress, directing by broadcast, regular evacuation rehearsal or experiment, and etc.

\subsection{Influence of Fire}

The CFD files obtained by SMARTFIRE can be input into Building EXODUS in order to simulate the evacuation process in the case of fire. Taking the total number of 500 for example, the evacuation time in the case of the fire simulated is $73.48 \mathrm{~s}$, which is a mean value of 10 times' calculations. Compared with the evacuation time of $47.78 \mathrm{~s}$ without fire, it is prolonged by $53.8 \%$ because of the decrease of walking speed and visibility, the change of route choice caused by fire, and etc.

No one evacuates from exit 9 and only one occupant evacuates from exit 8 because the fire source is located near the exit 8 and 9. As shown in Fig. 10, many occupants choose the exits far away from exit 8 and 9. The utilization ratio of exit 19 is $14.8 \%$, which is the maximum value in this case. While the minimum value is $0 \%$ appeared at exit 9 . The unbalance of the utilization ratios of each exit caused by fire is a very important reason for the increase of evacuation time. 


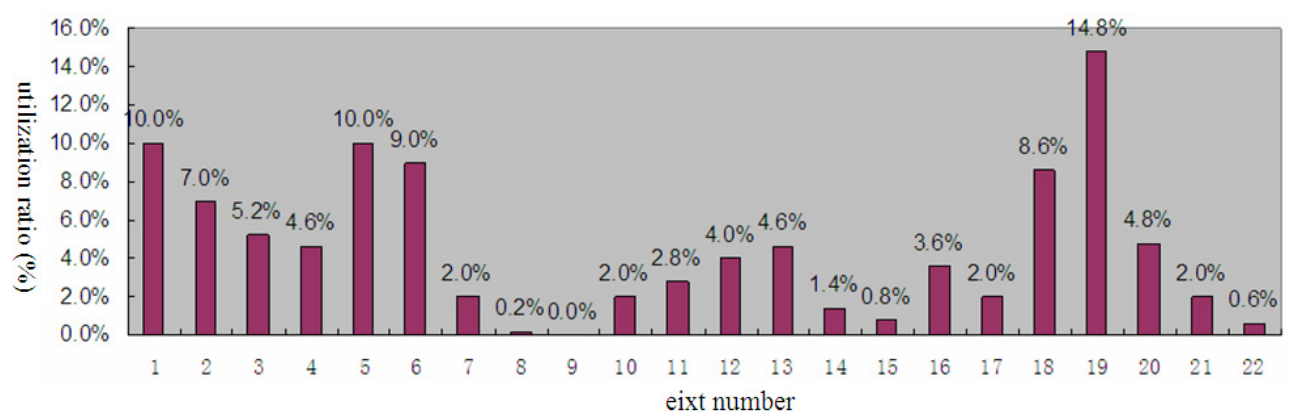

Figure 10. Utilization ratio of each exit in the case of the fire simulated

\section{Conclusions}

The software SMARTFIRE and BuildingEXODUS are applied to simulate the fire and evacuation process at a long-distance passenger transport station. Some conclusions can be summarized as below:

(1). The influence of the density of occupants on evacuation: Within the range of low density of occupants, the evacuation time changes a little with the increase of the total number of occupants if there are plenty of exits. The pedestrian flow takes on a dilute state; The evacuation time can only be affected when the density of occupants reaches to a certain degree and the phenomenon of queuing up at exits or other bottlenecks appears. The higher the density, the longer the evacuation time is. The pedestrian flow takes on a dense state for a long time during evacuation.

(2). The influence of utilization ratio of exit on evacuation: Taking the total number of 500 occupants into account, the evacuation time is $47.95 \mathrm{~s}$ when following the potential map is applied. In this case, the utilization ratios of each exit are very different; If the utilization ratios of each exit are balanced artificially by changing some occupants' evacuation routes, the evacuation time is reduced by $16 \%$, i.e. 40.32 s. Evacuation under some reasonable guidance is more efficient than that without any interference in case of emergency.

(3). The influence of fire on evacuation: Also taking the total number of 500 occupants into account, the evacuation time with and without the fire are $73.48 \mathrm{~s}$ and $47.78 \mathrm{~s}$, respectively. The former is much longer than the latter by $53.8 \%$. In addition to the reasons of the decrease of visibility and walking speed, the change of evacuation routes and unbalanced utilization ratio of each exit are also very important reasons.

\section{Acknowledgements}

This paper is supported by the Natural Science Foundation of Shanghai (Grant No. 15ZR1440900), the National Natural Science Foundation of China (Grant No. 51006072). The authors deeply appreciate the supports.

\section{References}

Buckmann, L. T., \& Leather, J. A. (1994). Modelling station congestion the PEDROUTE way. Traffic Engineering and Control, 35(6), 373-377.

David, J. L. (2000). Following the crowd. Nature, 407, 465-466. https://doi.org/10.1038/35035192

Ehtamo, H., Heliövaara, S., Korhonen, T., \& Hostikka, S. (2010).Game theoretic best-response dynamics for evacuees' exit selection. Advances in Complex Systems, 13, 113-134. https://doi.org/10.1142/S021952591000244X

Ewer, J., Jia, F., Grandison, A., Galea, E., \& Patel, M. (2008). SMARTFIRE V4.1 technical reference manual.

Galea e, R., Lawrence, P. J., Gwynne, S., Filippidis, L., Blackshields, D., \& Cooney, D. (2006). Building EXODUS V4.06 technical reference manual.

Helbing D. (1994).A mathematical model for the behavior of individuals in a social field. Journal of Mathematical Sociology, 19(3), 189-219. https://doi.org/10.1080/0022250X.1994.9990143

Helbing, D., Farkas, I., \& Vicsek, T. (2000). Simulating dynamical features of escape panic. Nature, 407, 489-490. https://doi.org/10.1038/35035023

Henderson, L. F. (1974). On the fluid mechanic of human crowd motions. Transportation Research, 8(6), 509-515. https://doi.org/10.1016/0041-1647(74)90027-6

Jiang, C. S., Deng, Y. F., Hu, C., Ding, H., \& Chow, W. K. (2009). Crowding in platform staircases of a subway station in China during rush hours. Safety Science, 47(7), 931-938. https://doi.org/10.1016/j.ssci.2008.10.003

Korhonen, T., Hostikka, S., Heliövaara, S., \& Ehtamo, H. (2008). FDS+Evac: modelling social interactions in fire evacuation. Proceedings of 7th International Conference on Performance-Based Codes and Fire Safety Design Methods. Auckland, New Zealand, SFPE (Bethesda, MD, USA, 2008), 241-250. 
Sun, C. Y., \& Bauke, de V. (2009). Automated human choice extraction for evacuation route prediction. Automation in Construction, 18(6), 751-761. https://doi.org/10.1016/j.autcon.2009.02.009

Zhao, D. L., Yang, L. Z., \& Li, J. (2006). Exit dynamics of occupant evacuation in an emergency. Physica A, 363(2), 501-511. https://doi.org/10.1016/j.physa.2005.08.012

Zhao, D. L., Yang, L. Z., Li, J., Zhu, Y., \& Zou, L. (2006). Relationship between performance-based design of building exits and state transition of pedestrian flow during occupant evacuation. Journal of Fire Protection Engineering, 16(4), 269-281. https://doi.org/10.1177/1042391506061523

\section{Copyrights}

Copyright for this article is retained by the author(s), with first publication rights granted to the journal.

This is an open-access article distributed under the terms and conditions of the Creative Commons Attribution license which permits unrestricted use, distribution, and reproduction in any medium, provided the original work is properly cited. 